\title{
Impact of land use/cover changes on carbon storage in a river valley in arid areas of Northwest China
}

\author{
YANG Yuhai $^{1}$, LI Weihong ${ }^{1 *}$, ZHU Chenggang ${ }^{1}$, WANG Yang ${ }^{2}$, HUANG Xiang ${ }^{1}$ \\ ${ }^{1}$ Key Laboratory of Oasis Ecology and Desert Environment, Xinjiang Institute of Ecology and Geography, Chinese Academy \\ of Sciences, Urumqi 830011, China; \\ ${ }^{2}$ College of Pratacultural and Environmental Sciences, Xinjiang Agricultural University, Urumqi 830052, China
}

\begin{abstract}
Soil carbon pools could become a $\mathrm{CO}_{2}$ source or sink, depending on the directions of land use/cover changes. A slight change of soil carbon will inevitably affect the atmospheric $\mathrm{CO}_{2}$ concentration and consequently the climate. Based on the data from 127 soil sample sites, 48 vegetation survey plots, and Landsat TM images, we analyzed the land use/cover changes, estimated soil organic carbon (SOC) storage and vegetation carbon storage of grassland, and discussed the impact of grassland changes on carbon storage during 2000 to 2013 in the Ili River Valley of Northwest China. The results indicate that the areal extents of forestland, shrubland, moderate-coverage grassland (MCG), and the waterbody (including glaciers) decreased while the areal extents of high-coverage grassland (HCG), low-coverage grassland (LCG), residential and industrial land, and cultivated land increased. The grassland SOC density in 0-100 $\mathrm{cm}$ depth varied with the coverage in a descending order of HCG $>$ MCG $>$ LCG. The regional grassland SOC storage in the depth of $0-100 \mathrm{~cm}$ in 2013 increased by $0.25 \times 10^{11} \mathrm{~kg}$ compared with that in 2000 . The regional vegetation carbon storage $\left(\mathrm{S}_{\mathrm{rvc}}\right)$ of grassland was $5.27 \times 10^{9} \mathrm{~kg}$ in 2013 and decreased by $15.7 \%$ compared to that in 2000. The vegetation carbon reserves of the under-ground parts of vegetation $\left(\mathrm{S}_{\text {ruvb }}\right)$ in 2013 was $0.68 \times 10^{9} \mathrm{~kg}$ and increased by approximately $19.01 \%$ compared to that in 2000. This research can improve our understanding about the impact of land use/cover changes on the carbon storage in arid areas of Northwest China.
\end{abstract}

Keywords: land use/cover; organic carbon; grassland; global change; Ili River Valley

Citation: YANG Yuhai, LI Weihong, ZHU Chenggang, WANG Yang, HUANG Xiang. 2017. Impact of land use/cover changes on carbon storage in a river valley in arid areas of Northwest China. Journal of Arid Land, 9(6): 879-887. https://doi.org/10.1007/s40333-017-0106-3

\section{Introduction}

Land use/cover change is widely recognized as a key driver of global carbon dynamics (Fang et al., 2007; Chen et al., 2010; Song et al., 2014) and thus plays a critical role in maintaining and building soil carbon (Mclauchlan et al., 2006; Stockmann et al., 2013 Were et al., 2016). Soil contains the largest organic carbon pool, approximately 2344,1550 , and $615 \mathrm{Pg} \mathrm{C}$ in $3.0,1.0$, and $0.2 \mathrm{~m}$ soil depths, respectively, in global terrestrial ecosystems (Lal, 2009). Moreover, the soil organic carbon (SOC) pool is 2.2 times of the atmospheric carbon pool and 2.8 times of the biomass carbon pool (Jobbágy and Jackson, 2000; Post and Kwon, 2000; Lal, 2004; Stockmann et al., 2013). SOC is relatively easy to change and inevitably affects atmospheric $\mathrm{CO}_{2}$ concentration (Sun et al., 2016). Under the influence of land use/cover change, soil carbon pools could become a source or sink of $\mathrm{CO}_{2}$ (Yao et al., 2010). Due to the high spatial heterogeneity of soil, the global

\footnotetext{
*Corresponding author: LI Weihong (E-mail: liwh@ms.xjb.ac.cn) Received 2017-02-08; revised 2017-09-13; accepted 2017-09-19

(C) Xinjiang Institute of Ecology and Geography, Chinese Academy of Sciences, Science Press and Springer-Verlag GmbH Germany 2017
} 
SOC reserves varied from areas to areas, ranging from 1220 to $2000 \mathrm{Pg} \mathrm{C}$ in $0-100 \mathrm{~cm}$ soil layer (Jobbágy and Jackson, 2000; Don et al., 2007; Tarnocaiet al., 2009). The conversion of farmland to grassland significantly increased soil carbon sequestration, but the opposite conversion resulted in a loss of SOC (Wang et al., 2009; Deng et al., 2014). Therefore, it is crucial to evaluate the SOC pool and its response to land use/cover changes for precise assessments on the global carbon cycle.

The Ili River Valley is located in arid areas of Northwest China and is a key region on the Silk Road Economic Belt. It is an area suffering from serious soil and water losses resulted from land use/cover changes (Kang and Zhang, 2012). The land use/cover change is a major driving force for soil carbon pool changes (Cheng et al., 2004). Our previous works (Yang et al., 2010) indicated that both SOC and SOC density $\left(\mathrm{D}_{\mathrm{soc}}\right)$ in the $0-50 \mathrm{~cm}$ soil horizon of meadows in the Ili River Valley were higher than those of temperate coniferous forest. During the period 2000-2013, grassland had experienced a major change in the Ili River Valley. How have these changes affect the grassland carbon pool there?

The objectives of this study were: (1) to analyze land use/cover changes, (2) to estimate the regional grassland carbon storage in the Ili River Valley, and (3) to discuss the influence of grassland changes on carbon storage during the period 2000-2013. Not only will this study obtain specific information on the effects of grassland changes on SOC stocks in the Ili RiverValley, but it will also provide regional information on the impact of regional policies on land use/cover changes.

\section{Materials and methods}

\subsection{Study area}

The Ili River Valley is located in the western part of the Tianshan Mountains $\left(42^{\circ} 14^{\prime} 16^{\prime \prime}-\right.$ $44^{\circ} 50^{\prime} 30^{\prime \prime} \mathrm{N}, 80^{\circ} 09^{\prime} 42^{\prime \prime}-84^{\circ} 56^{\prime} 56^{\prime \prime} \mathrm{E}$ ), China. The valley is surrounded by high mountains in the north, east and south. The terrain generally tilts towards the west and becomes narrower towards the east. The climate in the valley is dominated by the moderate temperate continental and alpine climates. It is generally warm and humid with a large diurnal temperature differences. The mean annual precipitation and annual mean air temperature range from 200 to $800 \mathrm{~mm}$ and $2.9^{\circ} \mathrm{C}$ to $9.1^{\circ} \mathrm{C}$, respectively. The precipitation increases significantly with altitude and the annul precipitation is $200-300 \mathrm{~mm}$ in low-elevation plain area and is greater than $1000 \mathrm{~mm}$ in high-elevation mountains. The mean annual precipitation at our study area, the Narat Grassland (above $1700 \mathrm{~m}$ a.s.l.) is greater than $800 \mathrm{~mm}$, and the mean annual evaporation is 1260-1900 $\mathrm{mm}$. The annual frost-free days are 130-180 d, and the mean annual sunshine hours are 2700$3000 \mathrm{~h}$. The detailed description of vegetation types in the valley can be found in Yang et al. (2010).

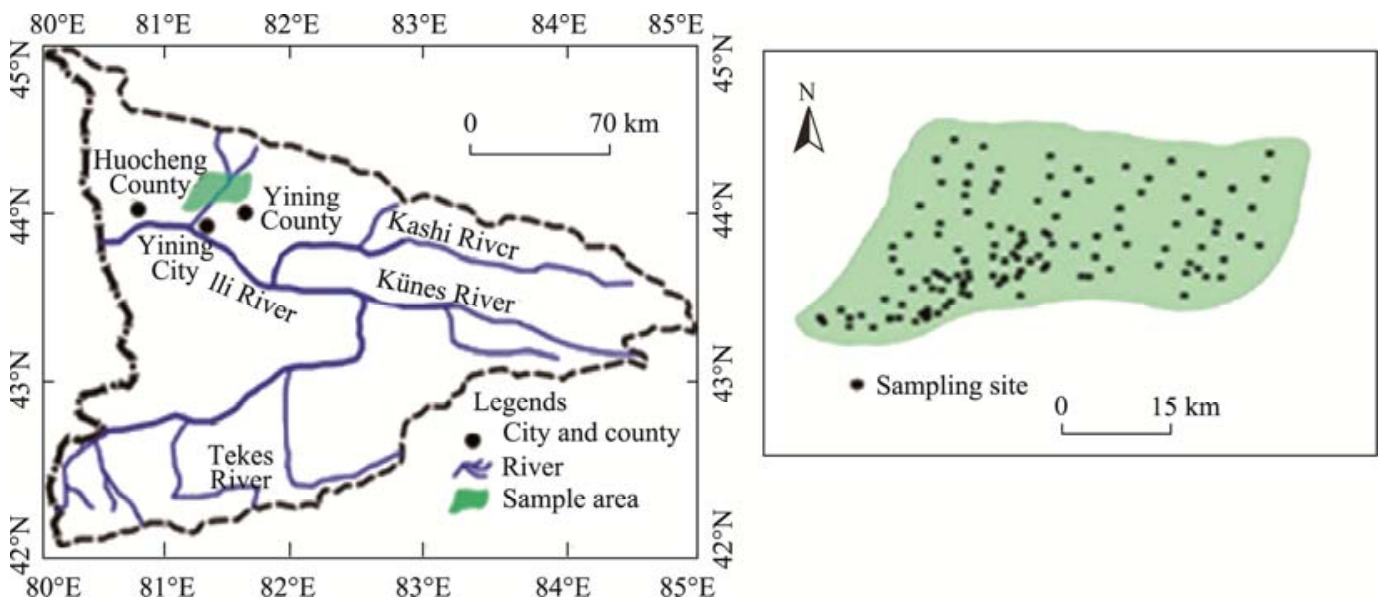

Fig. 1 Location of the study area and sampling sites 


\subsection{Soil sampling and vegetation survey}

The sampling area $\left(43^{\circ} 95^{\prime}-44^{\circ} 20^{\prime} \mathrm{N}, 81^{\circ} 05^{\prime}-81^{\circ} 55^{\prime} \mathrm{E}\right)$ was on the northern slope of the Ili River Valley, where the human disturbances are rather severe. The sampling sites were selected across a gradient level of human disturbances, a diversity of landscapes and vegetation (Fig. 1). Specifically, more samples were collected in the areas with higher level of human disturbances, more diverse landforms and vegetation. The land use/cover types in the sampling area included high-coverage grassland (HCG), moderate coverage grassland (MCG), low-coverage grassland (LCG), ecological forestland (EF), fruit forestland (FF), dry farmland (DF), and vineyards (VY).

The field work was conducted from May to June in 2015. The total soil sampling sites were 127 with 11, 45, 28, 13, 17, 7 and 6 sites in HCG, MCG, LCG, EF, FF, DF and VY, respectively. Each of the sampling sites was positioned by a global positioning system (GPS). Soil samples were taken with a soil auger at a depth of $0-20 \mathrm{~cm}$. We took five soil samples from five different points at each site and mixed them thoroughly to make it as the single representative sample for the site. Soil samples were sorted for roots and gravels, air-dried at room temperature, and then passed through a 2-mm sieve. Samples were subsequently analyzed in the laboratory for soil organic matter content $\left(\mathrm{K}_{2}-\mathrm{Cr}_{2} \mathrm{O}_{7}-\mathrm{H}_{2} \mathrm{SO}_{4}\right.$ Walkley-Black oxidation method; Laboratory of Soil Physics, 1978) and multiplied the soil organic matter content by the correction factor of 0.58 to obtain the organic carbon content.

Another set of 127 soil samples were collected in aluminum boxes at the exactly same sites and weighed in situ. The samples were later oven-dried at $105^{\circ} \mathrm{C}$ in the laboratory to measure soil moisture content.

To calculate the soil bulk density at the depth of $0-20 \mathrm{~cm}$, we collected three replicated undisturbed soil samples at each site using soil cores.

We also dug four soil profiles in the grassland. Soil samples were collected from the profiles with a shovel at depths of $0-5,5-10,10-15,15-20,20-30,30-50,50-70$, and $70-100 \mathrm{~cm}$. At each layer, we sampled the soil at five different points and mixed them to make it a single representative soil sample for the layer.

We only sampled the vegetation in the grassland and set 48 quadrats $(1 \mathrm{~m} \times 1 \mathrm{~m})$ to survey plant biomass according to the coverage. Above-ground parts of plants in each quadrat were mowed and kept in envelopes, and were later oven-dried at $65^{\circ} \mathrm{C}$ to obtain above-ground biomass. To measure the under-ground biomass, we first cleaned the residues and impurities on the ground and sampled the soil in volume of $30 \mathrm{~cm} \times 30 \mathrm{~cm} \times 30 \mathrm{~cm}$ in the quadrat. We then sieved the samples in situ and kept the visible roots. The visible roots were later rinsed with clean water and oven-dried at $65^{\circ} \mathrm{C}$ in laboratory to obtain under-ground vegetation biomass.

\subsection{Other data}

We identified the land use/cover changes during the period 2000-2013 based on the Landsat TM images of Landsat bands 5, 4, and 3 obtained on 8 August, 2000 and 2013. Good-quality images were selected. The land use/cover in the Ili River Valley is classified into waterbody, forestland, shrubland, high-coverage grassland (HCG), moderate coverage grassland (MCG), low-coverage grassland (LCG), cultivated land, residential and industrial land, and unused land according to the six-type classification system developed by the Resources and Environment Database of the Chinese Academy of Sciences. The classification was conducted using ENVI and ArcGIS, augmented by field trips with GPS. The LCG, MCG, HCG were defined as the coverage $>50 \%$, $20 \%-50 \%$, and $5 \%-20 \%$, respectively.

\subsection{Methods}

We selected $D_{\text {soc }}$, regional SOC storage $\left(S_{\text {soc }}\right)$, regional above-ground vegetation carbon storage $\left(\mathrm{S}_{\mathrm{rvc}}\right)$, and regional under-ground vegetation carbon storage $\left(\mathrm{S}_{\mathrm{ruvb}}\right)$ to analyze the carbon storage under the impact of the land use/cover changes in the Ili River Valley.

$\mathrm{D}_{\text {soc }}$ refers to the SOC reserve per unit area in a soil horizon with a specific depth and the specific depth is normally $1 \mathrm{~m}$, but it can be larger of smaller depending on soil cases. If a soil profile is comprised of a number of horizons, $D_{\text {soc }}\left(\mathrm{kg} / \mathrm{m}^{2}\right)$ of each soil horizon can be calculated 
by Equation 1 (Wang and Zhou, 1999).

$$
D_{\text {soc }}=S O C \times H \times D \times\left(100-V_{\text {cf }}\right) / 100,
$$

where $S O C$ is the SOC concentration $(\mathrm{g} / \mathrm{kg}) ; H$ is the depth $(\mathrm{cm})$ of a soil layer; $D$ is the soil bulk density $\left(\mathrm{g} / \mathrm{cm}^{3}\right)$ of the layer; and $V_{\text {cf }}$ is the volume $(\%)$ of coarse fragments $(>2 \mathrm{~cm})$. In this study, we calculated the $D_{\text {soc }}$ at the depth of $0-100 \mathrm{~cm}\left(D_{\text {soc } 100}\right)$ by adding the $D_{\text {soc }}$ of each soil layer in $0-100 \mathrm{~cm}$ depth.

$\mathrm{S}_{\mathrm{soc}}$ refers to the total SOC reserves within the region. It can be derived from the sum of the $\mathrm{S}_{\mathrm{soc}}$ of each soil layer, which can be obtained by multiplying the area of the region and the $\mathrm{D}_{\mathrm{soc}}$ of each soil layer. We calculated the $S_{\text {soc }}(\mathrm{kg})$ of each soil layer using Equation 2.

$$
S_{\text {soc }}=\mathrm{S} \times H \times D_{\text {soc }}
$$

where $S$ is the area of the region $\left(\mathrm{m}^{2}\right)$; $H$ is the depth $(\mathrm{cm})$ of a layer; and $D_{\text {soc }}$ is the SOC density $\left(\mathrm{kg} / \mathrm{m}^{2}\right)$ of the layer. We estimated the grassland $S_{\text {soc }}$ at the depth of $0-100 \mathrm{~cm}\left(S_{\text {soc } 100}\right)$ based on the $\mathrm{D}_{\mathrm{soc} 100}$.

$\mathrm{S}_{\mathrm{rvc}}$ refers to the vegetation carbon reserves of the above-ground parts of vegetation, which can be calculated by Equation 3 .

$$
S_{\mathrm{rvc}}=D_{\mathrm{avb}} \times A \times B,
$$

where $D_{\text {avb }}$ is the above-ground vegetation biomass density of the grassland $\left(\mathrm{g} / \mathrm{m}^{2}\right) ; A$ is the area of the grassland $\left(\mathrm{m}^{2}\right)$; and $\mathrm{B}$ is the coefficient of vegetation biomass converting to vegetation carbon. If land use type is forest, B is 0.5. If land use type is not forest, $B$ is 0.45 (Liu et al., 2010). In this study, we took $B$ as 0.45 when calculating the grassland $S_{\text {rvc }}$.

$\mathrm{S}_{\text {ruvb }}$ refers to the vegetation carbon reserves of the under-ground parts of vegetation and can be calculated by Equation 4.

$$
S_{\mathrm{ruvb}}=D_{\mathrm{uvb}} \times A \times B,
$$

where $D_{\text {uvb }}$ is the under-ground vegetation biomass density of grassland $\left(\mathrm{g} / \mathrm{m}^{2}\right) ; A$ is the area of grassland $\left(\mathrm{m}^{2}\right)$; and we took $B$ as 0.45 as well.

Based on the $D_{\text {avb }}$ and $D_{\text {uvb }}$ in 2015, combining the grassland areas in 2000 and 2013, we estimated the $\mathrm{S}_{\mathrm{rvc}}$ and $\mathrm{S}_{\mathrm{ruvb}}$ in 2000 and 2013, respectively.

\subsection{Statistical analysis}

We compared the effects of land use/cover change on the SOC among the different land use types using one-way analysis of variance and least significant difference $(P<0.05)$.

\section{Results}

\subsection{Land use/cover change}

Due to the human activities, the land use/cover experienced considerable changes in the Ili River Valley during the period 2000-2013 (Fig. 2). The areal extents of forestland, shrubland, MCG, and water bodies (including glaciers) started to decrease in 2000, while the areal extents of HCG, LCG, residential and industrial land, and cultivated land increased. In 2000, the areas of forestlands and shrublands accounted for $10.08 \%$ and $0.67 \%$ of the total area, respectively, and percentages were down to $6.41 \%$ and $0.16 \%$ in 2013 . However, the areal extent of grassland in 2013 was larger than that in 2000. Specifically, the HCG area and LCG area increased from $30.79 \%$ and $7.80 \%$ in 2000 to $42.53 \%$ and $8.44 \%$ in 2013 , respectively. In contrast, the MCG area decreased relatively significantly from 2000 to 2013. The waterbodies (including glaciers) decreased from $5.65 \%$ to $2.57 \%$, while the cultivated land, unused land, and residential and industrial land increased from $12.20 \%$ to $14.83 \%, 10.59 \%$ to $11.99 \%$, and $1.08 \%$ to $1.46 \%$, respectively.

\subsection{Grassland soil organic carbon}

The grassland $D_{\text {soc100 }}$ varied with vegetation coverage (Fig. 3a) in a descending order of HCG $>$ MCG $>$ LCG. Overall, the grassland $S_{\text {soc } 100}$ increased by $0.25 \times 10^{11} \mathrm{~kg}$ from 2000 to 2013 . 
Among the three types of the grasslands, $\mathrm{HCGS}_{\mathrm{soc} 100}$ increased by $1.25 \times 10^{11} \mathrm{~kg}, \mathrm{MCG} \mathrm{S}_{\mathrm{soc} 100}$ decreased by $0.87 \times 10^{11} \mathrm{~kg}$, and LCG $\mathrm{S}_{\mathrm{soc}}$ increased by $0.06 \times 10^{11} \mathrm{~kg}$ (Fig. $3 \mathrm{c}$ ).

Within soil profiles, SOC gradually decreased with soil depth, with the exception of the 50-70 $\mathrm{cm}$ layer where SOC was higher than the overlying layer (Fig. 3b). To further compare $\mathrm{D}_{\text {soc }}$ among the different soil layers, we set $5 \mathrm{~cm}$ as the standard height to calculate the $\mathrm{D}_{\text {soc }}\left(\mathrm{D}_{\text {soc } 5}\right)$ for each layer. As shown in Figure 3d, $D_{\text {soc } 5}$ decreased within the top 0-20 cm, then increased within the depth of 20-70 cm (Fig. 3d), and decreased below $70 \mathrm{~cm}$. In the profile, the highest SOC appeared in the $0-5 \mathrm{~cm}$ soil layer but the highest $\mathrm{D}_{\text {soc5 }}$ occurred in $50-70 \mathrm{~cm}$ layer. This demonstrates that SOC cannot be used instead of $D_{\text {soc }}$ to reflect $S_{\text {soc. }}$.
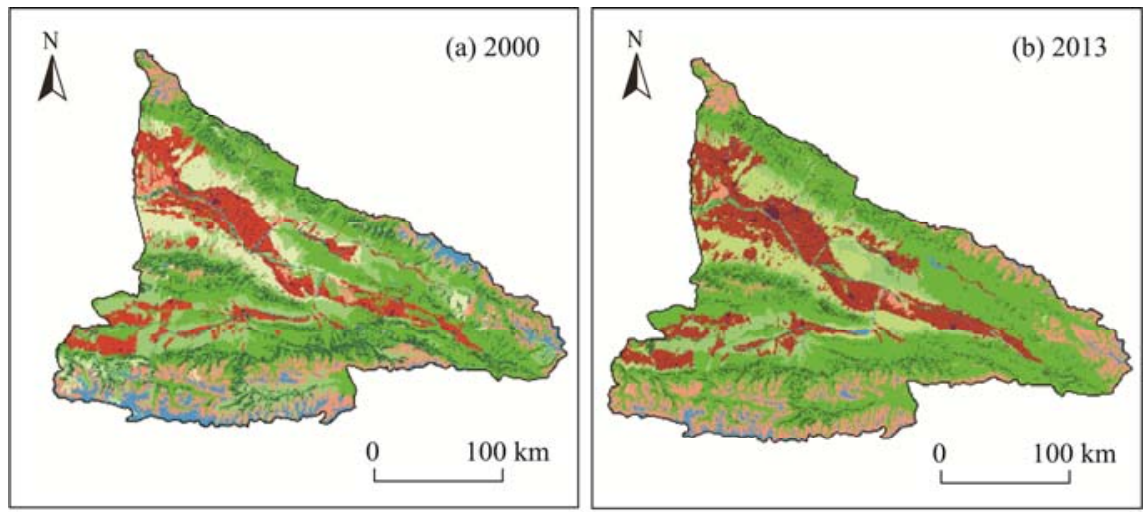

Legend

Forest land

Shrubland

Waterbody

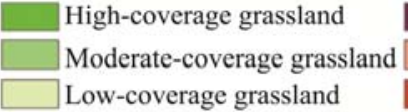

Residential and industry area Unused land

Cultivated land

Fig. 2 Land use/cover changes in the Ili River Valley during the period 2000-2013
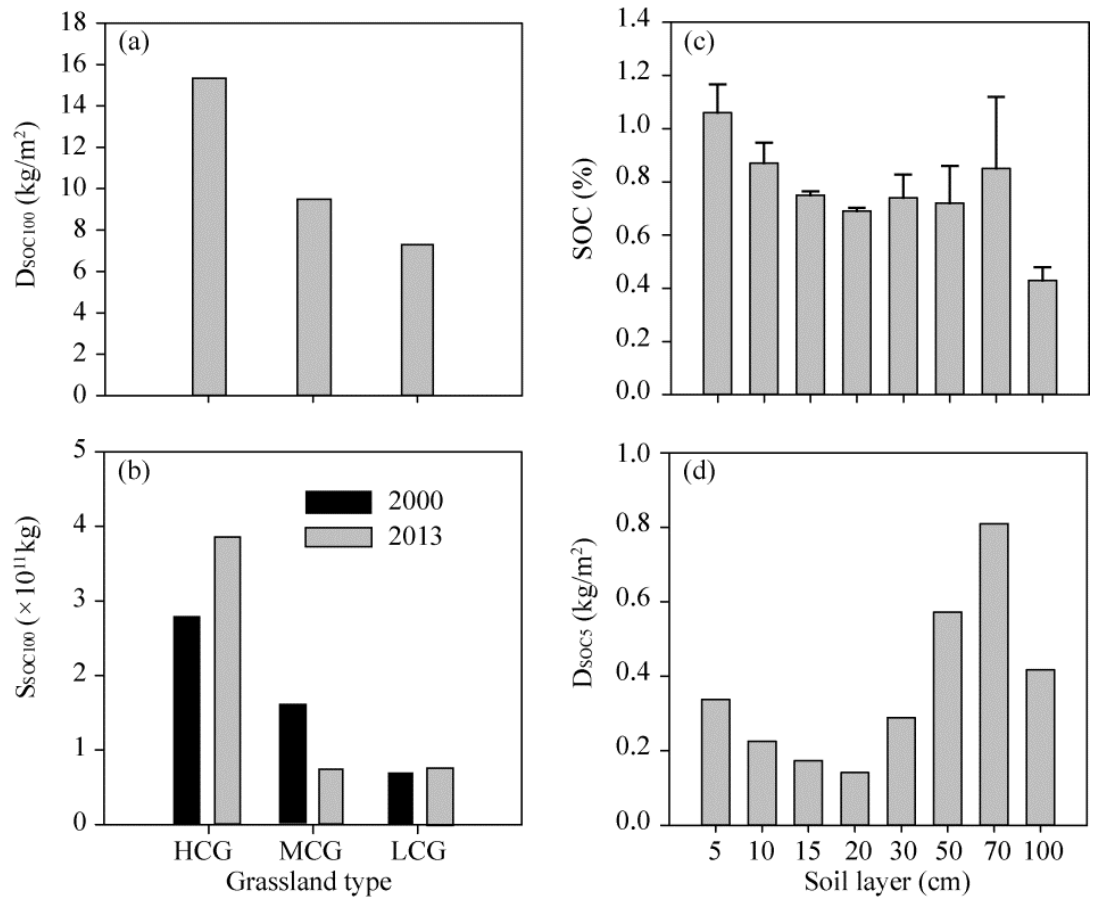

Fig. 3 Soil organic carbon (SOC) in the grassland under different coverage and soil depths. 5, 10, 15, 20, 30, 50, 70 and $100 \mathrm{~cm}$ stand for the soil layers of $0-5,5-10,10-15,15-20,20-30,30-50,50-70$, and $70-100 \mathrm{~cm}$, respectively. $\mathrm{D}_{\mathrm{SOC} 100}, \mathrm{SOC}$ density at the depth of $0-100 \mathrm{~cm}$; $\mathrm{S}_{\mathrm{SOC} 100}$, the grassland regional SOC storage at the depth of 0-100 cm; $\mathrm{D}_{\mathrm{SOC} 5}$, $\mathrm{SOC}$ density with a standard height of $5 \mathrm{~cm}$; HCG, high-coverage grassland; MCG, moderate-coverage grassland; LCG, low-coverage grassland. Bars mean standard errors. 


\subsection{Above-ground and under-ground vegetation carbon storage in grassland}

The grassland $\mathrm{D}_{\mathrm{avb}}$ varied with vegetation coverage (Fig. 4a) in a descending order of $\mathrm{MCG}>\mathrm{HCG}>\mathrm{LCG}$. Overall, the grassland $\mathrm{S}_{\mathrm{rvc}}$ was $5.27 \times 10^{9} \mathrm{~kg}$ in 2013 and decreased by $15.7 \%$ over that in 2000. The HCG and LCG $\mathrm{S}_{\mathrm{rvc}}$ increased by $38.3 \%$ and $8.3 \%$ during 2000-2013, respectively. However, the MCG $\mathrm{S}_{\mathrm{rvc}}$ decreased by 54.1\% from 2000 to 2013 (Fig. 4c). The vegetation coverage had an effect on the $\mathrm{D}_{\text {uvb }}$ of grassland (Fig. $4 \mathrm{~b}$ ). The highest $\mathrm{D}_{\text {uvb }}$ was in the HCG, while the lowest in the LCG. The $\mathrm{S}_{\text {ruvb }}$ in 2013 was $0.68 \times 10^{9} \mathrm{~kg}$ and increased by approximately $19.01 \%$ over that in 2000 (Fig. 4d).

There was a significant correlation between $\mathrm{D}_{\text {uvb }}$ and $\mathrm{D}_{\mathrm{avb}}(P=0.031<0.05, n=45)$ in the grassland and the correlation between $\mathrm{D}_{\mathrm{uvb}}(y)$ and $\mathrm{D}_{\mathrm{avb}}(x)$ can be expressed as: $y=-$ $9.95+0.099 x-7.1 \times 10-5 x^{2}(P=0.009<0.05)$.

\subsection{Influence of land use/cover on soil organic carbon}

Land use/cover affected the SOC and the $\mathrm{D}_{\text {soc100. }}$. The SOC of grassland was higher than those of forestland and DF (Fig. 5). The highest and lowest SOC and $\mathrm{D}_{\text {soc } 100}$ appeared in the HCG and VY, respectively. The FF SOC is significantly different from those under the other land use/cover types. However, there was no significant difference among VY and EF, and DF and LCG. The $\mathrm{D}_{\mathrm{soc} 100}$ is in a descending order of $\mathrm{HCG}>\mathrm{MCG}>\mathrm{LCG}>\mathrm{EF}>\mathrm{FF}>\mathrm{DF}>\mathrm{VY}$.
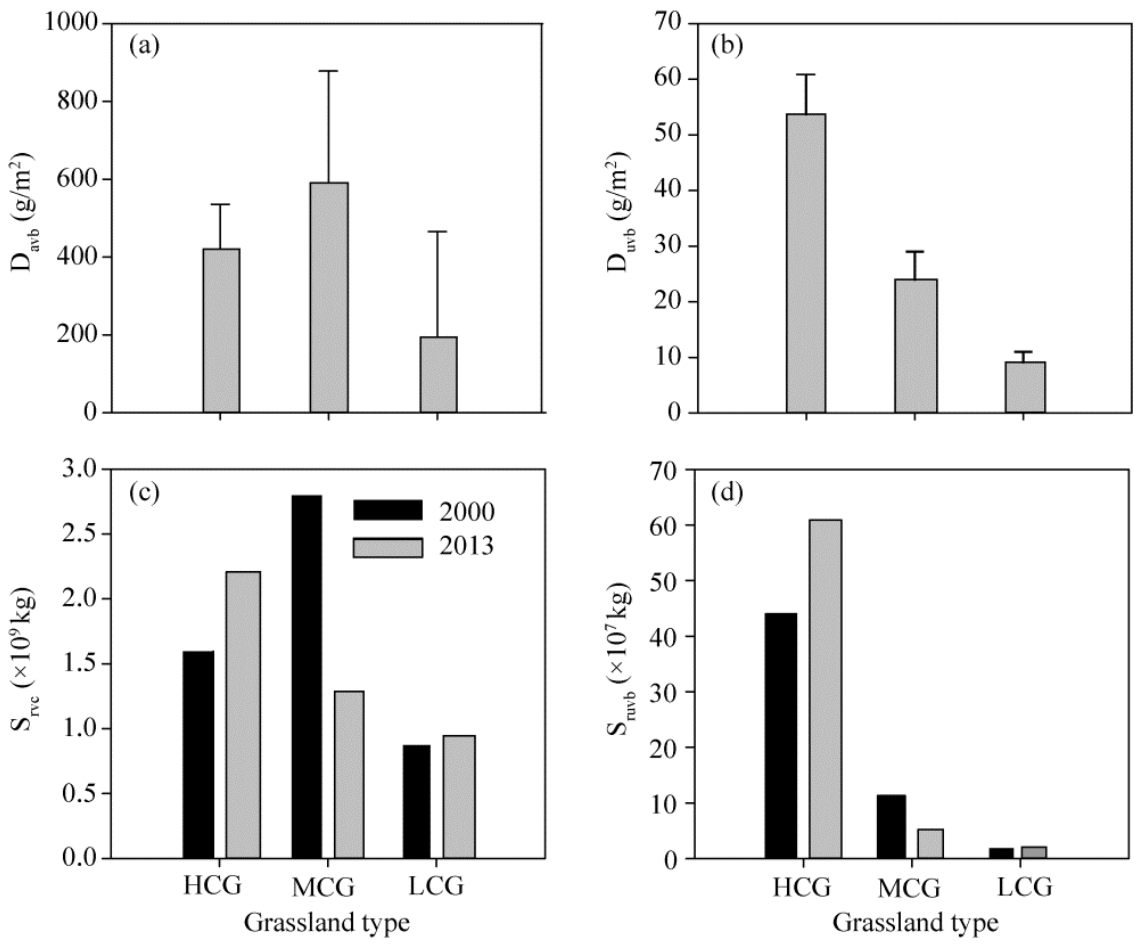

Fig. 4 Vegetation carbon in grassland under different coverage. $\mathrm{D}_{\text {avb }}$, above-ground vegetation biomass density; $\mathrm{D}_{\mathrm{uvb}}$, under-ground vegetation biomass density; $\mathrm{S}_{\mathrm{rvc}}$, regional vegetation carbon storage; $\mathrm{S}_{\mathrm{ruvb}}$, regional under-ground vegetation carbon storage. Bars mean standard errors.

\section{Discussion}

\subsection{Land use/cover and soil organic carbon}

SOC can reflect the dynamic status of an ecological system under certain conditions (Fu et al., 2004; Jia et al., 2004; Zhou et al., 2005). SOC accumulation varies greatly depending on climatic conditions and human disturbances (Fu et al., 2004). Vegetation coverage, grassland productivity, and rainfall are the main factors influencing surface SOC. Our research indicates that the grassland SOC is intuitively highest in HCG, moderate in MCG and lowest in LCG. In our 

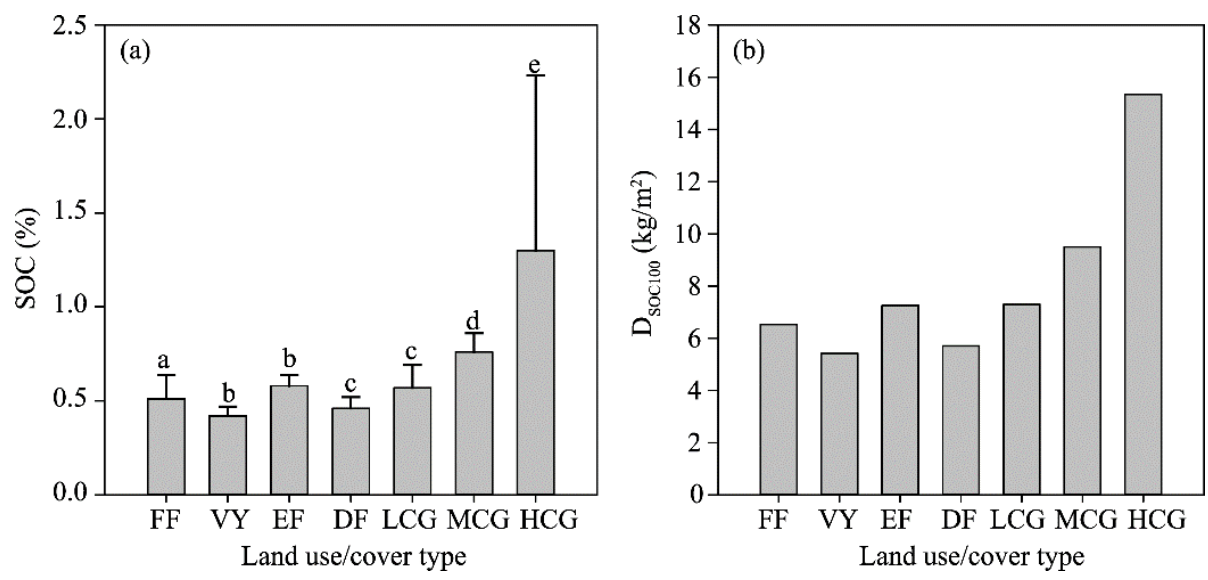

Fig. 5 SOC and $D_{\text {soc } 100}$ in different land use types. The lowercase letters denote significant difference among land use/cover types at $P<0.05$ level. FF, fruit forestland; VY, vineyard; EF, ecological forestland; DF, dry farmland. Bars mean standard errors.

research, the grassland $\mathrm{D}_{\text {soc100 }}$ was higher than that of DF, showing that the conversion of grassland to DF can decrease the $\mathrm{D}_{\text {soc }}$ in the Ili River Valley. Therefore, natural grassland was the optimal choice for increasing soil carbon storage.

The $D_{\text {soc }}$ values of the $0-20 \mathrm{~cm}$ soil layer varied with the vegetation types. For example, the values were $3.77,4.70$ and $2.56 \mathrm{~kg} / \mathrm{m}^{2}$ under coniferous forest, broadleaved forest, and scrub (Xie et al., 2004), respectively. In the Ili River Valley, the grassland $D_{\text {soc }}$ of the $0-20 \mathrm{~cm}$ soil layer estimated by the SOC $\left(2.02 \mathrm{~kg} / \mathrm{m}^{2}\right)$ was significantly lower than that under the forestland (Xie et al., 2004), showing that $S_{\text {soc }}$ of grassland is significantly lower than that of forestland in the Ili River Valley.

\subsection{Land use/cover and vegetation carbon storage}

Our results indicate that SOC at the $0-5 \mathrm{~cm}$ depth in DF and VY are lower than that in MCG. This shows that change of land use/cover can affect surface SOC, being supportive to the researches of Batjes and Dijkshoorn (1999), and Batjes and Sombroek (1997). The $\mathrm{D}_{\text {soc }}$ in MCG was lower than that in HCG while the $\mathrm{D}_{\text {avb }}$ in MCG was higher than that in HCG. This may be due to the differences in plant species. Our field survey shows that gramineae herb, with rich fine roots, is the main herb for HCG, while non-gramineae herbs, such as Sophoraalopecuroides with much above-ground biomass and less roots, is the main grass for MCG.

\subsection{Changes of grassland types and carbon storage}

The above-ground vegetation carbon densities for LCG, MCG, and HCG in our study were 8.77, 26.58 , and $18.93 \mathrm{~kg} \mathrm{C} / \mathrm{hm}^{2}$, respectively, which were far lower than those of grassland in the Tibet Plateau (44.542-1620.895 kg C/hm ${ }^{2}$ (Wang et al., 2009)). Ma et al. (2014) reported that the overall $\mathrm{D}_{\text {avb }}$ values $\left(4.3-731.3 \mathrm{~g} / \mathrm{m}^{2}\right)$ were much lower than the overall $\mathrm{D}_{\text {uvb }}$ values $(44.6-4899.5$ $\mathrm{g} / \mathrm{m}^{2}$ ) in Chinese grasslands. Our research found that the $D_{\text {avb }}$ was approximately 10 times of the $\mathrm{D}_{\mathrm{uvb}}$ in Illi grasslands, being contradictive to the research by Ma et al. (2014). This may be due to the differences in sampling times. In spring, the growth rate of the above-ground part exceeds the growth rate of the under-ground part. The root-shoot ratio then begins to decrease with the rise in temperature in July and August and the ratio of under-ground biomass to above-ground biomass is the smallest (Chai et al., 2014). In our research, we surveyed the vegetation biomass in July, the sampling time (Jule) may lead to the ratio of under-ground biomass to above-ground biomass being too small. Mokany et al. (2006) reported that more than $62 \%$ of the reported data regarding the under-ground biomass to above-ground biomass ratio (root-shoot ratio) are not acceptable for representing the yearly ratios and the non-acceptability was most likely due to the sampling-depth differences. Because of the difficulty in obtaining the under-ground biomass data, other studies used the root-shoot ratio to estimate the under-ground biomass and the root-shoot ratio method 
may have increased the estimation errors of the grassland vegetation carbon stocks (Ma et al., 2010). In our study, we used the measured data to estimate the grassland vegetation carbon stock and the estimates should be more acceptable.

This study shows that the relationship between the grassland $D_{a v b}$ and $D_{u v b}$ can be expressed by a quadratic mode while the relationship between the above-ground biomass and under-ground biomass in other ecosystems (e.g., alpine meadow, warm desert grassland, and alpine grassland) can be expressed a power mode. However, Ma et al. (2014) found no obvious relationship between the above-ground biomass and the under-ground biomass in mountain meadows. These different results indicate that the relationship between the above-ground biomass and under-ground biomass should be further investigated.

The grassland $\mathrm{S}_{\mathrm{rvc}}$ in 2013 was less than that in 2000. This might be caused by the changes in the areas of the grassland and the associated changes in the $\mathrm{D}_{\mathrm{avb}}$. In MCG, the $\mathrm{D}_{\text {avb }}$ was the highest among the three types of grasslands, but the areal extent of MCG declined the most. The combined effects of the increased $\mathrm{D}_{\mathrm{avb}}$ and the decreased areal extent make the MCG $\mathrm{S}_{\mathrm{rvc}}$ in 2013 smaller than that in 2000 .

The areal extents of HCG and LCG increased, whereas the areal extent of MCG decreased during the period 2000-2013. The increase in HCG and LCG may be directly related to the government polices to protect the grasslands from overgrazing. But, fencing (protecting) and overgrazing on MCG coexisted. Coverage change directly affects not only the grassland vegetation carbon storage, but also the terrestrial ecosystem carbon cycle. The conversion from low-coverage to high-coverage can increase $\mathrm{D}_{\mathrm{soc}}$ in the grassland. The conversion from high-coverage to moderate-coverage, low-coverage, and other land use/cover types may lead to a decline in grassland $\mathrm{D}_{\mathrm{soc}}$, thus resulting in a reduction of $\mathrm{S}_{\mathrm{soc}}$ in the grassland.

\section{Conclusion}

Land use/cover plays an important role in carbon storage in the terrestrial ecosystems. The areal extents of forestland, shrubland, MCG and waterbody (including glaciers) decreased from 2000 to 2013, while the areal extents of HCG, LCG, residential and industrial land, unused land, and cultivated land increased. The land use/cover change had a strong impact on both the $\mathrm{S}_{\mathrm{rvc}}$ and $\mathrm{S}_{\mathrm{soc}}$ in the region. The overall grassland $S_{\text {rvc }}$ decreased during the period 2000-2013 and the overall grassland $\mathrm{S}_{\text {soc }}$ increased during the same period. The overall increase of $\mathrm{S}_{\text {soc }}$ was resulted from the increases in the areal extents of HCG and LCG, but not MCG that experienced a decline in the areal extent.

\section{Acknowledgements}

This work was financially supported by the National Science and Technology Support Plan (2014BAC15B03), the National Natural Science Foundation of China $(41371503,41371128)$ and the West Light Foundation of the Chinese Academy of Sciences (YB201302).

\section{References}

BatjesN H, Sombroek W G. 1997. Possibilities for carbon sequestration in tropical and subtropical soils. Global Change Biology, 3(2): 161-173.

BatjesN H, Dijkshoorn J A. 1999. Carbon and nitrogen stocks in the soils of the Amazon Region. Geoderma, 89(3-4): 273-286.

Chai X, Liang C Z, Liang M W, et al. 2014. Seasonal dynamics of belowground biomass and productivity and potential of carbon sequestration in meadow steppe and typical steppe, in Inner Mongolia, China. Acta Ecologica Sinica, 34(19): 55305540. (in Chinese)

Chen Z S, Chen Y N, Li W H, et al. 2010. Evaluating effect of land use change on environment in Ili Valley based on ecosystem service value analysis. Journal of Desert Research, 30(4): 870-877. (in Chinese)

Cheng S L, Ouyang H, Niu H S, et al. 2004. Temporal-spatial dynamic analysis of soil organic carbon in inversed desertification area: A case study in Yulin County, Shaanxi Province. Acta Geographica Sinica, 59(4): 505-513. (in Chinese)

Deng L, Shangguan Z P, Sweeney S. 2014. "Grain for Green" driven land use change and carbon sequestration on the Loess 
Plateau, China. Scientific Reports, 4: 7039.

Don A, Schumacher J, Scherer-Lorenzen M, et al. 2007. Spatial and vertical variation of soil carbon at two grassland sites-implications for measuring soil carbon stocks. Geoderma, 141(3-4): 272-282.

Fang J Y, Guo Z D, Piao S L, et al. 2007. Terrestrial vegetation carbon sinks in China, 1981-2000. Science in China Series D: Earth Sciences, 50(9): 1341-1350.

Fu H, Chen Y N, Wang Y R, et al. 2004. Organic carbon content in major grassland types in Alex, Inner Mongolia. Acta Ecologica Sinica, 24(3): 469-476. (in Chinese)

Jia X H, Zhou H Y, Li X R. 2004. Primary conclusion of soil organic carbon and total nitrogen variation in planted sand regions without irrigation. Journal of Desert Research, 24(4): 437-441. (in Chinese)

Jobbágy E G, Jackson R B. 2000. The vertical distribution of soil organic carbon and its relation to climate and vegetation. Ecological Applications, 10(2): 423-436.

Kang L, Zhang H Q. 2012. Assessment of the land desertification sensitivity of newly reclaimed area in Yili, Xinjiang. Resources Science, 34(5): 896-902. (in Chinese)

Laboratory of Soil Physics, Institute of Soil Science, Chinese Academy of Sciences. 1978. Methods of Soil Physic Measurement. Beijing: Science Press. (in Chinese)

Lal R. 2004. Soil carbon sequestration impacts on global climate change and food security. Science, 304(5677): $1623-1627$.

Lal R. 2009. Sequestering carbon in soils of arid ecosystems. Land Degradation \& Development, 20(4): 441-454.

Liu M Y, Bao A M, Chen X, et al. 2010. Impact of land use/cover change on the vegetation carbon storage in the Manas River Basin between 1976 and 2007. Journal of Natural Resources, 25(6): 926-938. (in Chinese)

Ma A N, Yu G R, He N P, et al. 2014. Above-and below ground biomass relationships in China's Grassland vegetation. Quaternary Sciences, 34(4): 769-776. (in Chinese)

Ma W H, Fang J Y, Yang Y H, et al. 2010. Biomass carbon stocks and their changes in northern China's grasslands during 1982-2006. Science China Life Sciences, 53(7): 841-850.

McLauchlan K K, Hobbie S E, Post W M. 2006. Conversion from agriculture to grassland builds soil organic matter on decadal timescales. Ecological Applications, 16(1): 143-153.

Mokany K, Raison R J, Prokushkin A S. 2006. Critical analysis of root: Shoot ratios in terrestrial biomes. Global Change Biology, 12(1): 84-96.

Post W M, Kwon K C. 2000. Soil carbon sequestration and land-use change: processes and potential. Global Change Biology, 6(3): 317-327.

Song X H, Peng C H, Zhou G M, et al. 2014. Chinese Grain for Green Program led to highly increased soil organic carbon levels: A meta-analysis. Scientific Reports, 4: 4460.

Stockmann U, Adams M A, Crawford J W, et al. 2013. The knowns, known unknowns and unknowns of sequestration of soil organic carbon. Agriculture, Ecosystems \& Environment, 164: 80-99.

Sun C L, Xue S, Chai Z Z, et al. 2016. Effects of land-use types on the vertical distribution of fractions of oxidizable organic carbon on the Loess Plateau, China. Journal of Arid Land, 8(2): 221-231.

Tarnocai C, Canadell J G, Schuur E A G, et al. 2009. Soil organic carbon pools in the northern circumpolar permafrost region. Global Biogeochemical Cycles, 23(2): 2607-2617.

Wang J L, Chang T J, Li P, et al. 2009. The vegetation carbon reserve and its spatial distribution configuration of grassland ecosystem in Tibet. Acta Ecologica Sinica, 29(2): 931-938. (in Chinese)

Wang Q, Zhang L, Li L, et al. 2009. Changes in carbon and nitrogen of Chernozem soil along a cultivation chronosequence in a semi-arid grassland. European Journal of Soil Science, 60(6): 916-923.

Wang S Q, Zhou C H. 1999. Estimating soil carbon reservoir of terrestrial ecosystem in China. Geographical Research, 18(4): 349-356. (in Chinese)

Were K, Singh B R, Dick Ø B. 2016. Spatially distributed modelling and mapping of soil organic carbon and total nitrogen stocks in the Eastern Mau Forest Reserve, Kenya. Journal of Geographical Sciences, 26(1): 102-124.

Xie X L, Sun B, Zhou H Z, et al. 2004. Soil carbon stocks and their influencing factors under native vegetation in China. Acta Pedologica Sinica, 41(5): 687-699. (in Chinese)

Yang Y H, Chen Y N, Li W H, et al. 2010. Distribution of soil organic carbon under different vegetation zones in the Ili River Valley, Xinjiang. Journal of Geographical Sciences, 20(5): 729-740.

Yao MK, Angui P K T, Konaté S, et al. 2010. Effects of land use types on soil organic carbon and nitrogen dynamics in MidWest Côte d'Ivoire. European Journal of Scientific Research, 40: 211-222.

Zhou L, Li B G, Zhou G S. 2005. Advances in controlling factors of soil organic carbon. Advances in Earth Science, 20(1): 99105. (in Chinese) 